\title{
Capsule-strip- An Unusual Cause of Acute Gastric Outlet Obstruction: A Case-Report
}

\author{
Rowshon $\mathrm{AHM}^{1}$, Uddin $\mathrm{AKMR}^{2}$
}

\begin{abstract}
A male patient presented with seven days history of severe epigastric colicky pain and vomiting. The patient was anxious and dehydrated. Blood tests and ultrasound reports were unremarkable. . Upper Gastrointestinal (GI) Endoscopy revealed a strip of capsule impacted at pyloric ring which was removed endoscopically and the patient became symptom free. [J Shaheed Suhrawardy Med Coll, 2013;5(1):67-68]
\end{abstract}

Keywords: Capsule-strip, Acute Gastric Outlet Obstruction, GOO

Received: December 2012; Revised: March 2013; Accepted: May 2013

\section{Introduction}

Gastric outlet obstruction is a well known condition in GI practice. But acute gastric outlet obstruction is relatively uncommon. In general, most upper GI tract obstruction are due to foreign bodies related to food impaction, with meat being the most frequent culprit ${ }^{1}$. Bezoars with or without impaction of migrated gall stone and acute inflammation in annular pancreas are also commoner causes of acute Gastric outlet obstruction ${ }^{2}$. Gastric bezoars are usually formed by indigestible plant material (phytobezoars), ingested hair (trichobe zoars), conglomerations of medications or medication vehicles (pharmacobezoars), or the combination of any of the above ${ }^{3}$. Ingestion of nondegradable solid items can sometimes get impacted at pyloric opening or channel and may cause acute gastric outlet obstruction. In this present case report patient with acute gastric outlet obstruction due to capsule-strip was discussed which is an unusual cause of acute GOO.

\section{Case Presentation}

A 56 years male patient from Kushtia district which is around $200 \mathrm{KM}$ from Dhaka city presented with seven days history of acute colicky upper abdominal pain, nausea and vomiting. Pain did not radiate, and was not associated with jaundice, fever or bowel alteration. The patient did not have chest-pain, respiratory difficulties or sweating.
The patient was hungry and thirsty and his urinary output was less and of high colour, though it was not reddish.

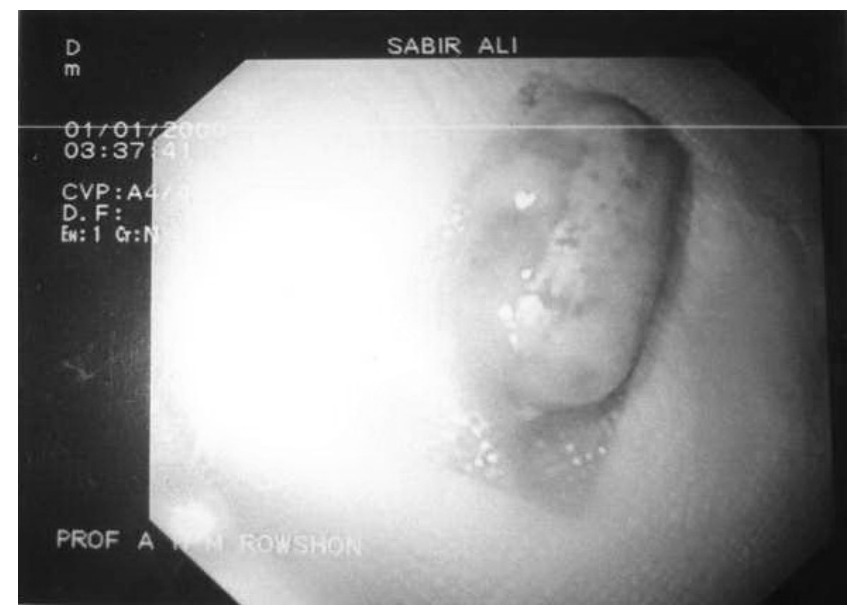

Figure I: Capsule-strip Removed

The patient had a history of mild dyspeptic upper abdominal pain for which he would take anti-ulcer drugs on occasions. On examination, the patient was found anxious, dehydrated with tachycardiac pulse rate with low blood pressure. On physical examination, abdomen was found mildly distended in epigastric and left hypochondriac region.

1. Prof. A H M Rowshon, Professor, Department of Gastroenterology, Shaheed Suhrawaedy Medical College, Dhaka

2. Prof. AKM Rafique Uddin, Professor, Department of Medicine, Enam Mesical College, Dhaka

\section{Correspondence}

Prof. A H M Rowshon, Professor, Department of Gastroenterology, Shaheed Suhrawaedy Medical College, Sher-E-Bangla Nagar, Dhaka-1207,

Bangladesh; Cell No: +8801711544368; E- mail: ahmrowshon@yahoo.com 


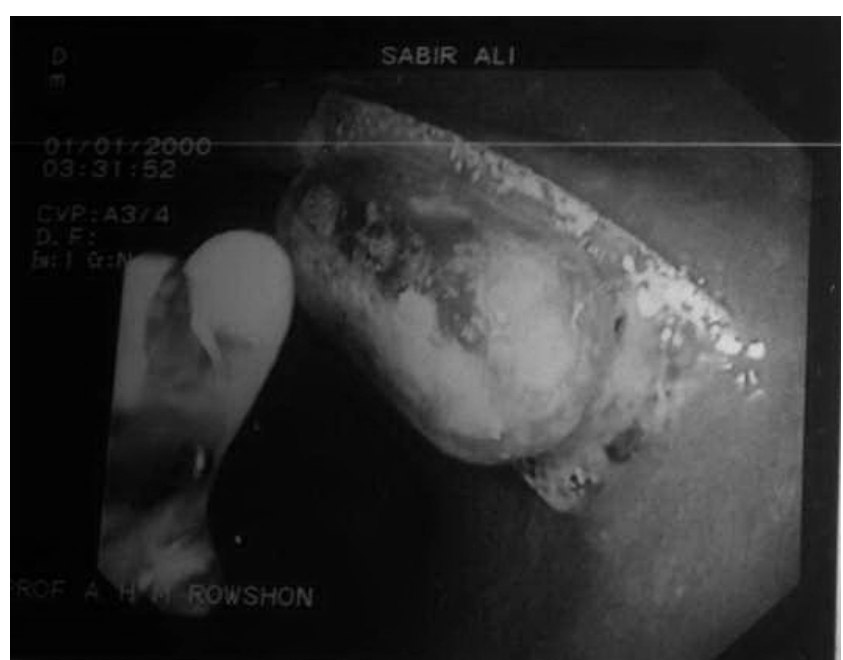

Figure II: Capsule-strip in Pyloric Ring

Mild tenderness was also found in the epigastrium. No organomegally or mass was detected on examination. Blood counts were normal, liver Function tests including serum bilirubin, Alanine aminotransferase, Alkaline Phosphatase level and Prothombin time were normal. Serum Amylase and serum lipase values were within normal limits. Serum urea and serum creatinine level were mildly elevated. Electrolytes and blood glucose were normal. Ultrasound examination of abdomen revealed no abnormality. ECG was found normal; chest X-ray and Xray abdomen showed normal findings.

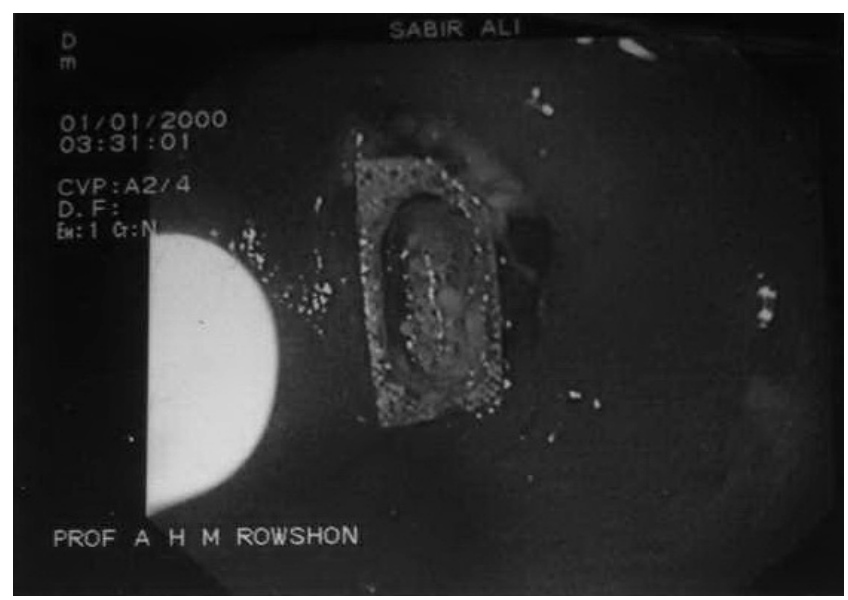

Figure III: Capsule-strip Removing

On upper GI endoscopy, moderate amount of residual food and secretion was found in stomach. The pyloric opening was partially obscured by food and could not be negotiated even on repeated attempts. After washing the area with water-jet, a white yellow bag-like thing was seen at the pyloric opening. On careful observation, a projection at one corner of the obstructing element was noticed. Through the working channel of endoscope, by the foreign body forceps, the substance was removed. On removal, it was surprisingly found to be nothing but the strip of a capsule which the patient took inadvertently and could not remember to mention. After removal of the strip, the patient felt well and started to take foods and drinks as before without any pain or vomiting.

\section{Discussion}

Peptic ulcer disease is the common cause of gastric outlet obstruction $^{2}$. However with the advent of proton pump inhibitors, the complications from peptic ulcer disease have drastically decreased ${ }^{4}$. These cause chromic gastric obstruction. On the other hand, GI bezoara are common causes of recurrent abdominal pain or acute upper GI obstruction. A history of foreign body ingestion, especially in children, mentally impaired and old patients, is important ${ }^{5}$. Common predisposing factors are previous gastric surgery, psychiatric illness, coeliac disease and metabolic disorders such as uraemia ${ }^{6}$. Rarely, bezoars can cause serious problems due to complications such as perforation ${ }^{7}$.

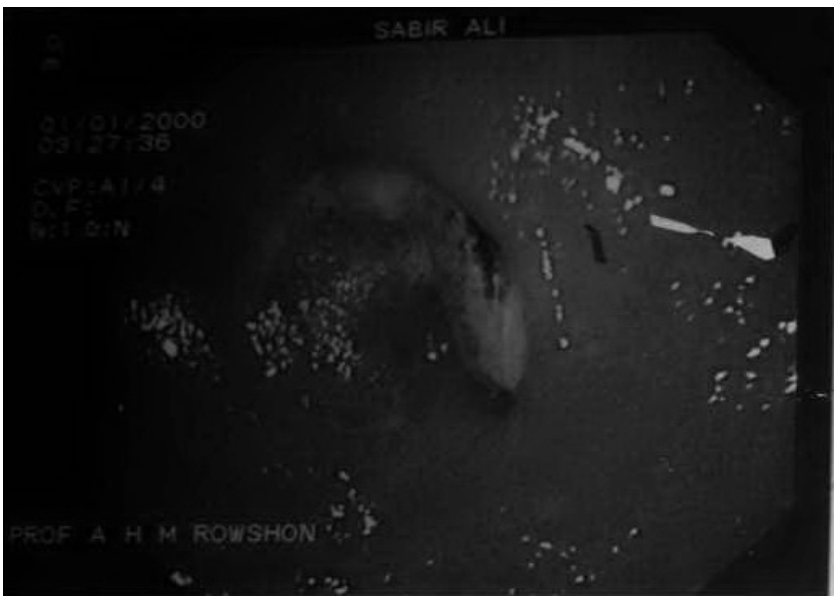

Figure IV: Capsule-strip

Therefore, anybody who presents with features of acute upper GI obstruction, a meticulous history of ingestion including drugs and others are very important especially in children, mentally retarded and old patient and in those who had previous abdominal operations. Endoscopy, is not only an investigating tool but also a good option for therapeutic approach for acute gastric outlet obstruction.

\section{References}

1. Conway WC, Sugawa C, Ono H, Lucas CE. Upper GI foreign body: an adult urban emergency hospital experience. Surg Endosc 2007, 21:455-460 2. Bitton A, Keagle JN, Varma MG. Small bowel bezoar in a patient with Noonan syndrome: report of a case. MedGenMed 2007;21(1):9-34

3. Sanders MK. Bezoars: from mystical charms to medical and nutritional management. Pract Gastroenterol 2004;28:37-50

4. Johnson CD. Gastric outlet obstructionmalignant until provenotherwise. Am J Gastroenterol. 1995;90:1740

5. Hussain A, Geddoa E, Abood M, Alazzawy M. Trichobezoar causing small bowel obstruction. S Afr Med J. 2007;97:343-344

6. El Fortia M. Duodenal obstruction secondary to date stone impaction. Ultraschall Med. 2007;28:79-81

7. Oktar SO, Erba F; G, Yucel C, Aslan E, Ozdemir H. Closed perforation of the small bowel secondary to a phytobezoar: imaging findings. Diagn Interv, 2007, 13:19-22 